\title{
Survival in sinonasal and middle ear malignancies: a population-based study using the SEER 1973-2015 database
}

\author{
Mitchell R. Gore (D)
}

\begin{abstract}
Background: The sinuses, nasal cavity, and middle ear represent a rarer location of head and neck malignancy than more common sites such as the larynx and oral cavity. Population-based studies are a useful tool to study the demographic and treatment factors affecting survival in these malignancies.

Methods: Population-based database search of the Survival, Epidemiology, and End Results (SEER) database from 1973 to 2015 for malignancies involving the nasal cavity, paranasal sinuses, and middle ear. Data were analyzed for demographics, treatment type, stage, primary site and histopathologic type. Kaplan-Meier analysis was used to assess and compare survival.

Results: A total of 13,992 cases of sinonasal or middle ear malignancy were identified and analyzed. The majority of patients were between ages 50 and 80 at the time of diagnosis. Overall 5-, 10-, and 20-year survival was 45.7\%, $32.2 \%$, and $16.4 \%$, respectively. Lymph node metastasis was reported in $4.4 \%$ of patients, while distant metastasis was present in $1.5 \%$ of cases. On univariate analysis surgical vs. nonsurgical treatment, sex, race, age at diagnosis, T stage, N stage, M stage, AJCC overall stage, primary site, tumor grade, and histopathologic subtype significantly affected survival. On multivariate analysis age, race, sex, primary site, overall AJCC stage, surgical vs. nonsurgical treatment, and $\mathrm{T}, \mathrm{N}$, and $\mathrm{M}$ stage remained significant predictors of overall survival.

Conclusions: Malignancies of the nasal cavity, paranasal sinuses, and middle ear account for a minority of overall head and neck cancers. The overall 5-, 10-, and 20-year survival for these malignancies is relatively low. Higher T, $\mathrm{N}, \mathrm{M}$, and overall stage and higher tumor grade is associated with lower survival. Patients treated with surgery as part of the treatment regimen had higher overall survival. Demographics and primary site also significantly affect survival. Certain histopathologic subtypes were associated with poorer survival.
\end{abstract}

Keywords: Head and neck Cancer, SEER, Survival, Kaplan-Meier, Sinonasal Cancer, Middle ear Cancer

\section{Background}

Malignancies of the head and neck comprise a diverse group of histopathological subtypes and tumor subsites. The majority of head and neck cancers are found in the oral cavity, oropharynx, and larynx. Malignancies of the nasal cavity, paranasal sinuses, and middle ear are far less common, with an incidence of less than 1 per 100,000 people and less than $20 \%$ of total head and neck malignancies $[1,2]$. Symptoms in patients with sinonasal

Correspondence: mgoremdphd@gmail.com

Department of Otolaryngology, State University of New York Upstate Medical University, Physicians Office Building North, Suite 4P, 4900 Broad Road, Syracuse, NY 13215, USA

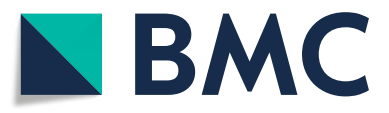

(c) The Author(s). 2018 Open Access This article is distributed under the terms of the Creative Commons Attribution 4.0 International License (http://creativecommons.org/licenses/by/4.0/), which permits unrestricted use, distribution, and reproduction in any medium, provided you give appropriate credit to the original author(s) and the source, provide a link to the Creative Commons license, and indicate if changes were made. The Creative Commons Public Domain Dedication waiver (http://creativecommons.org/publicdomain/zero/1.0/) applies to the data made available in this article, unless otherwise stated. 
sinus, and middle ear malignancy from the updated 1973-2015 Survival, Epidemiology, and End Results (SEER) database. The study examined the correlation between survival outcomes and the AJCC (American Joint Committee on Cancer) stage, tumor grade, tumor type, treatment type, tumor $(\mathrm{T})$, nodal $(\mathrm{N})$, and distant metastasis $(\mathrm{M})$ stage, patient age at diagnosis, patient sex, and patient race.

\section{Methods}

The most recent SEER database contains patient data from 1973 to 2015. Maintained by the National Cancer Institute, SEER collects data on cancer cases from various locations and sources throughout the United States, including various hospitals across many different states. The database, available at https://seer.cancer.gov/, was queried for malignant neoplasm, nose, nasal cavity, and middle

Table 1 Patient demographics

\begin{tabular}{|c|c|c|}
\hline & $n$ & $\%$ \\
\hline \multicolumn{3}{|l|}{ Demographics } \\
\hline Total & 13,992 & $100 \%$ \\
\hline Female & 5751 & $41.1 \%$ \\
\hline Male & 8242 & $58.9 \%$ \\
\hline Black & 1311 & $9.4 \%$ \\
\hline $\begin{array}{l}\text { Other (American Indian/AK } \\
\text { Native, Asian/Pacific Islander) }\end{array}$ & 1188 & $8.5 \%$ \\
\hline Unknown & 99 & $0.7 \%$ \\
\hline White & 11,395 & $81.4 \%$ \\
\hline \multicolumn{3}{|l|}{ Age at diagnosis } \\
\hline 00 years & 7 & $0.05 \%$ \\
\hline 01-04 years & 51 & $0.4 \%$ \\
\hline 05-09 years & 57 & $0.4 \%$ \\
\hline 10-14 years & 64 & $0.5 \%$ \\
\hline $15-19$ years & 112 & $0.8 \%$ \\
\hline 20-24 years & 128 & $0.9 \%$ \\
\hline $25-29$ years & 178 & $1.3 \%$ \\
\hline 30-34 years & 280 & $2.0 \%$ \\
\hline 35-39 years & 421 & $3.0 \%$ \\
\hline 40-44 years & 626 & $4.5 \%$ \\
\hline 45-49 years & 891 & $6.4 \%$ \\
\hline 50-54 years & 1228 & $8.8 \%$ \\
\hline $55-59$ years & 1459 & $10.4 \%$ \\
\hline $60-64$ years & 1650 & $11.8 \%$ \\
\hline 65-69 years & 1633 & $11.7 \%$ \\
\hline 70-74 years & 1537 & $11.0 \%$ \\
\hline $75-79$ years & 1444 & $10.3 \%$ \\
\hline $80-84$ years & 1162 & $8.3 \%$ \\
\hline $85+$ years & 1065 & $7.6 \%$ \\
\hline
\end{tabular}

ear, any subsite, any age, and was extracted using SEER*Stat version 8.3.5 (National Cancer Institute, Bethesda, Maryland) and exported into Microsoft Excel 2016 (Microsoft Corporation, Redmond, Washington) for analysis. XLstat Biomed (Addinsoft, New York City, NY/Paris, France) was used for Kaplan-Meier overall survival analysis and log-rank analysis. Statistical significance was set at 0.05 . SEER data was analyzed for overall survival, patient age, sex, and race, and overall AJCC (American Joint Committee on Cancer), tumor ( $\mathrm{T})$, nodal $(\mathrm{N})$, and distant metastasis (M) stage, surgical treatment, histopathological type, and primary tumor site.

\section{Results}

A total of 13,992 patients with malignancies of the nasal cavity, paranasal sinuses, and middle ear were identified from the 1973-2015 SEER database. Patient demographics

Table 2 Tumor histopathological types

\begin{tabular}{|c|c|c|}
\hline Histopathological subtype & $n$ & $\%$ \\
\hline unspecified neoplasms & 247 & $1.8 \%$ \\
\hline epithelial neoplasms, NOS & 1202 & $8.6 \%$ \\
\hline squamous cell neoplasms & 7116 & $50.9 \%$ \\
\hline basal cell neoplasms & 76 & $0.5 \%$ \\
\hline transitional cell papillomas and carcinomas & 128 & $0.9 \%$ \\
\hline adenomas and adenocarcinomas & 1768 & $12.6 \%$ \\
\hline adnexal and skin appendage neoplasms & 15 & $0.1 \%$ \\
\hline mucoepidermoid neoplasms & 190 & $1.4 \%$ \\
\hline cystic, mucinous and serous neoplasms & 94 & $0.7 \%$ \\
\hline ductal and lobular neoplasms & 27 & $0.2 \%$ \\
\hline acinar cell neoplasms & 24 & $0.2 \%$ \\
\hline complex epithelial neoplasms & 93 & $0.7 \%$ \\
\hline paragangliomas and glomus tumors & 3 & $0.02 \%$ \\
\hline nevi and melanomas & 1062 & $0.8 \%$ \\
\hline soft tissue tumors and sarcomas, NOS & 125 & $0.9 \%$ \\
\hline fibromatous neoplasms & 91 & $0.7 \%$ \\
\hline myomatous neoplasms & 388 & $2.8 \%$ \\
\hline complex mixed and stromal neoplasms & 78 & $0.6 \%$ \\
\hline synovial-like neoplasms & 9 & $0.06 \%$ \\
\hline germ cell neoplasms & 29 & $0.2 \%$ \\
\hline trophoblastic neoplasms & 1 & $0.007 \%$ \\
\hline blood vessel tumors & 52 & $0.4 \%$ \\
\hline osseous and chondromatous neoplasms & 97 & $0.7 \%$ \\
\hline miscellaneous tumors & 48 & $0.3 \%$ \\
\hline gliomas & 13 & 0.1 \\
\hline neuroepitheliomatous neoplasms & 972 & $7.0 \%$ \\
\hline meningiomas & 2 & $0.01 \%$ \\
\hline nerve sheath tumors & 42 & $0.3 \%$ \\
\hline granular cell tumors \& alveolar soft part sarcoma & 1 & $0.007 \%$ \\
\hline
\end{tabular}


Table 3 Tumor primary sites

\begin{tabular}{lll}
\hline Primary site & $\mathrm{n}$ & $\%$ \\
\hline Nasal cavity & 6455 & $46.1 \%$ \\
Middle ear & 439 & $3.1 \%$ \\
Maxillary sinus & 4449 & $31.8 \%$ \\
Ethmoid sinus & 1205 & $8.6 \%$ \\
Frontal sinus & 152 & $1.1 \%$ \\
Sphenoid sinus & 442 & $3.2 \%$ \\
Overlapping lesion of accessory sinuses & 281 & $2.0 \%$ \\
Accessory sinus, NOS & 570 & $4.1 \%$ \\
\hline
\end{tabular}

are summarized in Table 1 . The majority of patients were $>50$ years old, with age 60-64 years representing the largest group (1650/13992; 11.8\%). There was a male predominance, with a 8242:5751 M:F ratio (1.4:1). Patients were $81.4 \%$ white $(11,395 / 13992)$, with black patients representing 9.4\% (1311/13992), other (American Indian/ Alaska (AK) Native, Asian/Pacific Islander) representing 8.5\% (1188/13992), and 0.7\% (99/13992) unknown. Table 2 summarizes the histopathological data from the cohort. Squamous cell neoplasms $(7116,50.9 \%)$ and adenomas and adenocarcinomas $(1768,12.6 \%)$ were the most common tumor types. Table 3 summarizes the primary site data from the cohort. Nasal cavity $(6455,46.1 \%)$, maxillary sinus $(4449,31.8 \%)$, and ethmoid sinus $(1205,8.6 \%)$ were the most common primary sites.

Figure 1 shows the Kaplan-Meier actuarial overall survival for the entire cohort. Five-year, 10-year, and 20-year overall survival was $45.7 \%, 32.2 \%$, and $16.4 \%$, respectively. Figure 2 shows the Kaplan-Meier overall survival by primary site. Five-, 10-, and 20-year survival was highest for nasal cavity and middle ear tumors and lowest for maxillary sinus and frontal sinus tumors $(p<0.001)$. Figure 3 illustrates the Kaplan-Meier overall survival by overall AJCC (American Joint Committee on Cancer) stage. Survival was significantly lower for Stage III and IV tumors than Stage I and II tumors $(p<0.0001)$. Figure 4 shows the Kaplan-Meier overall survival by tumor $(\mathrm{T})$ stage. Survival decreased with increasing $\mathrm{T}$ stage $(p<0.0001)$. Figure 5 shows the Kaplan-Meier overall survival by nodal $(\mathrm{N})$ stage. Survival decreased with increasing $\mathrm{N}$ stage $(p<0.0001)$. Figure 6 illustrates the Kaplan-Meier overall survival by $M$ stage. Survival was significantly lower for M1 patients than M0 patients $(p<0.0001)$. Figure 7 illustrates the Kaplan-Meier overall survival for patients treated with surgery as part of their treatment regimen vs. patients for whom surgery was not recommended. Overall survival was lower for patients for whom surgery

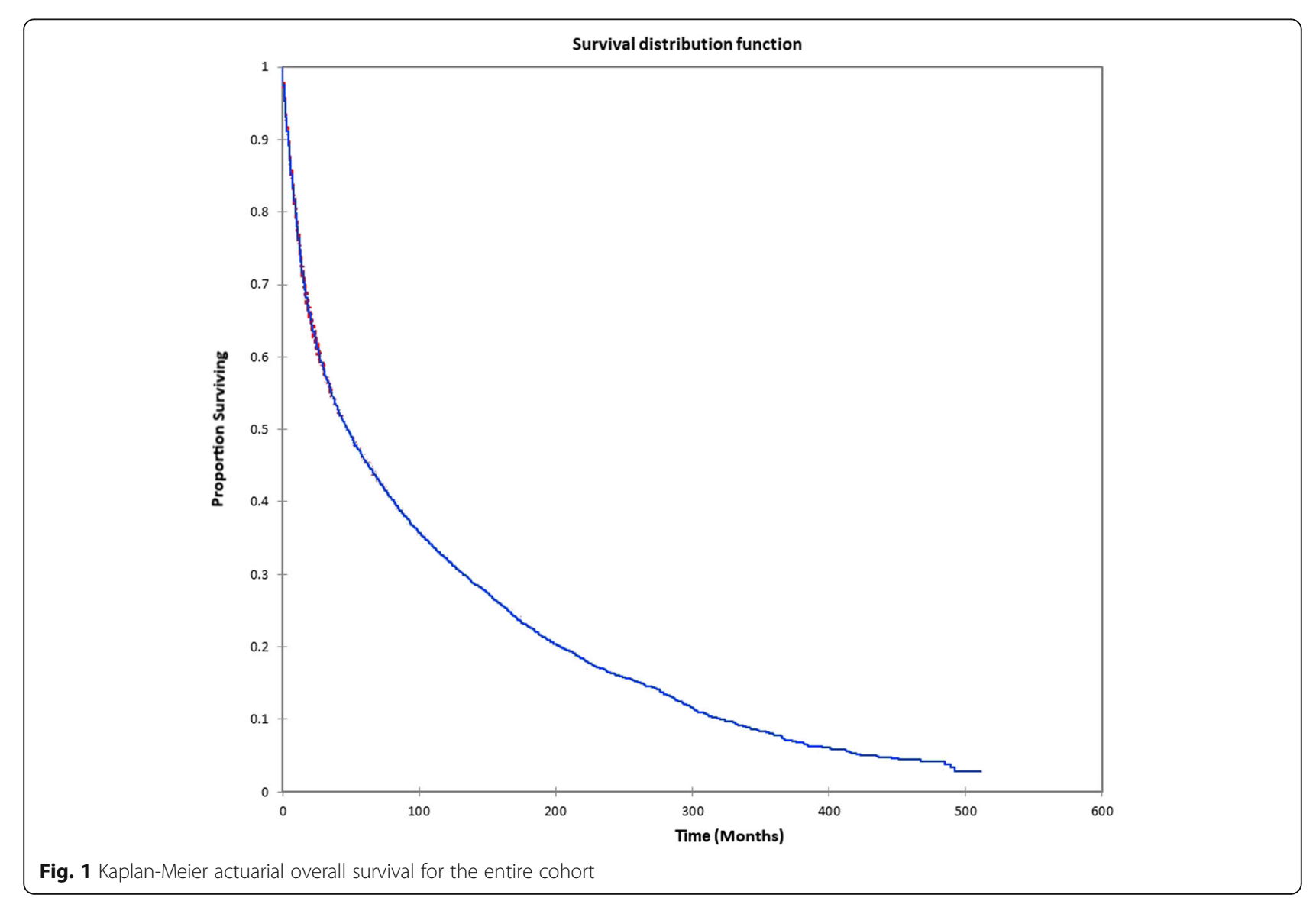




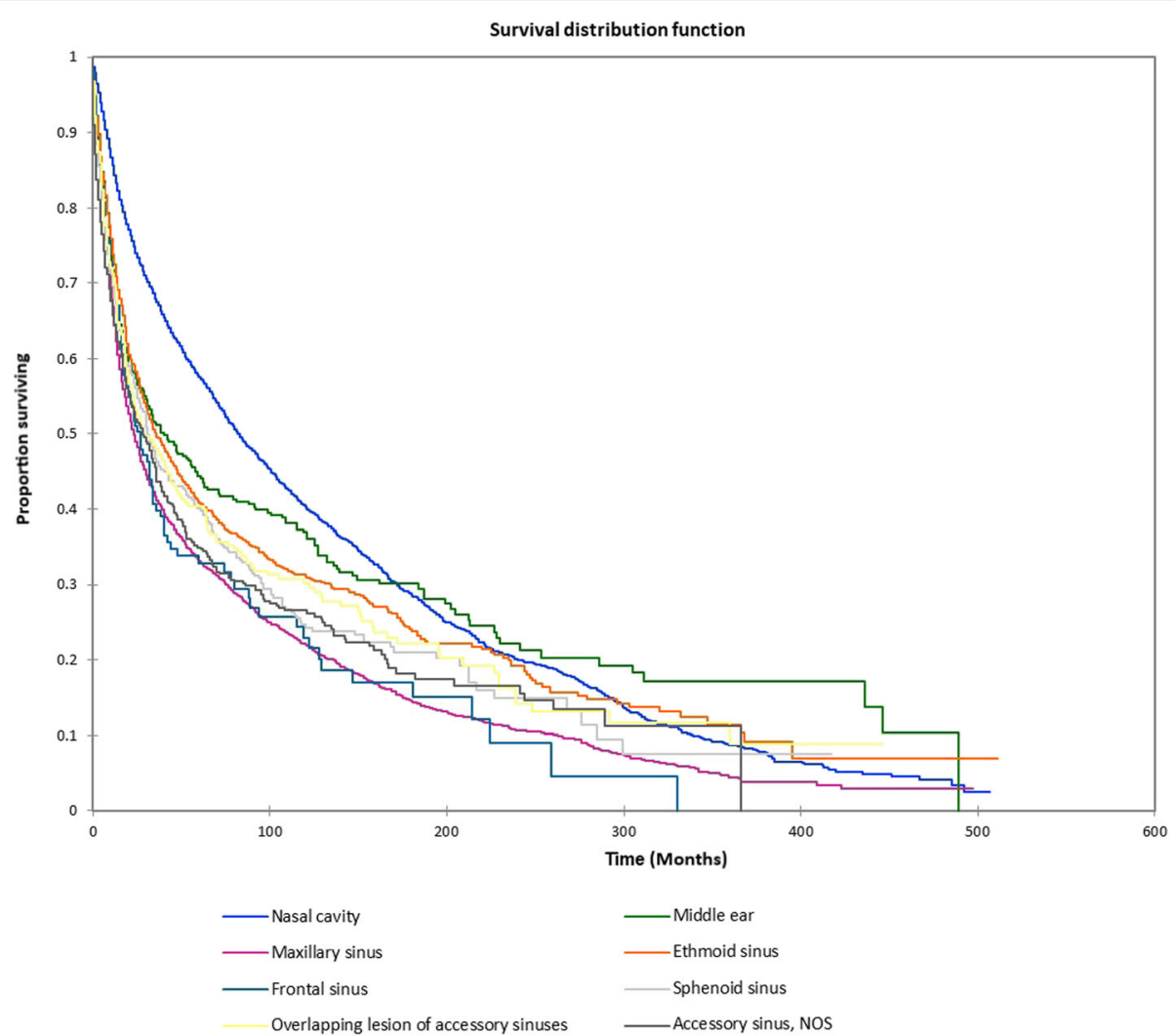

Fig. 2 Kaplan-Meier actuarial overall survival by primary site

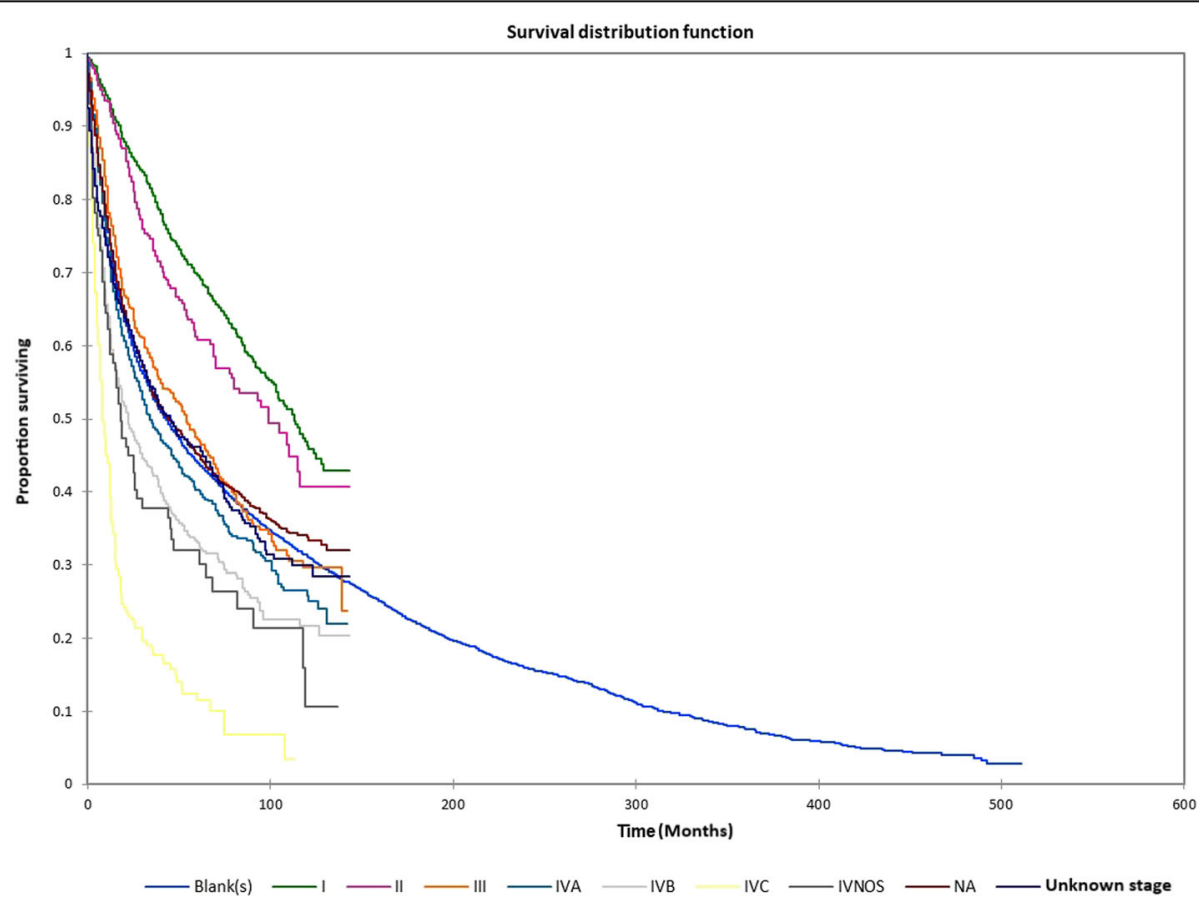

Fig. 3 Kaplan-Meier actuarial overall survival by AJCC stage 


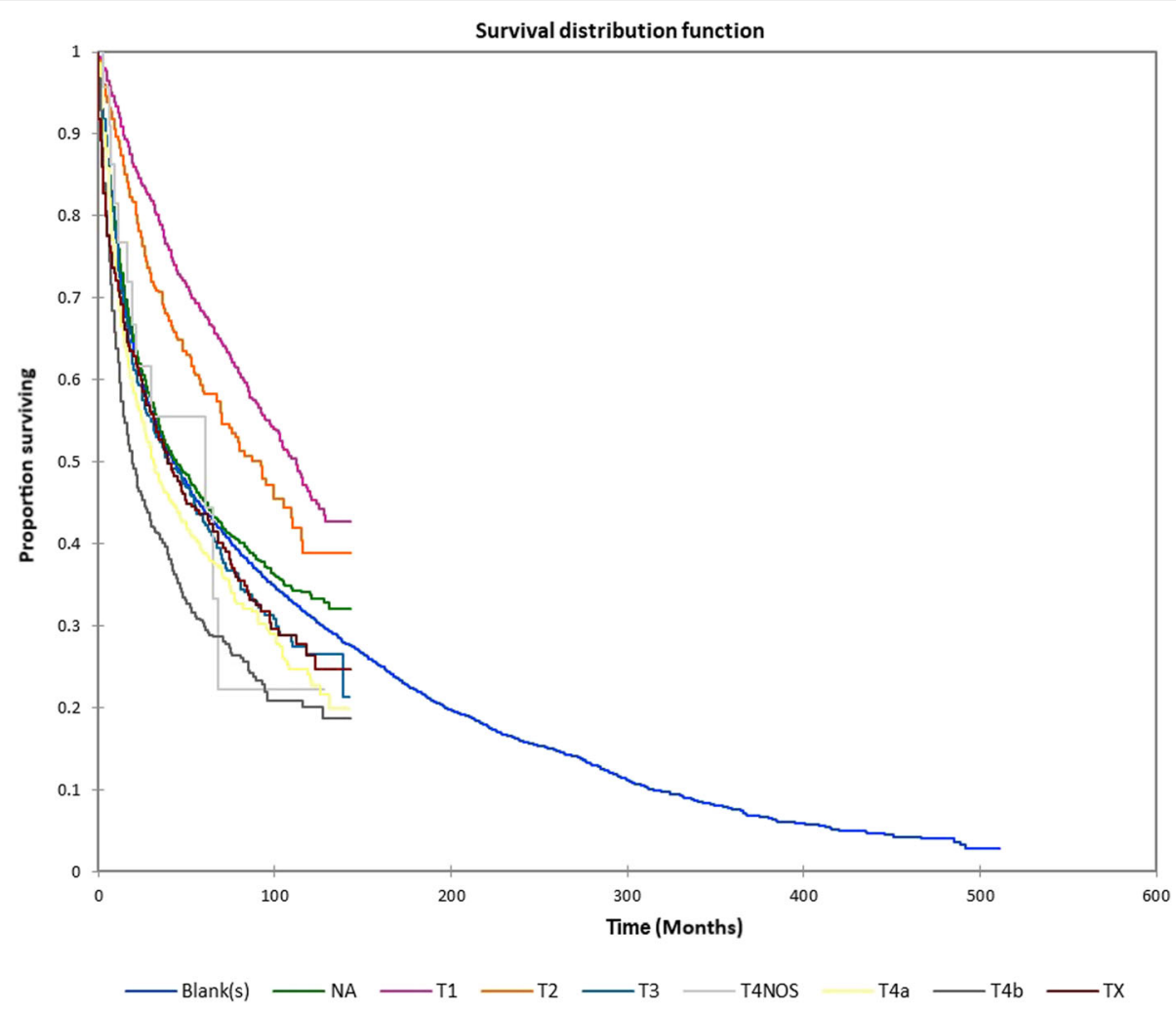

Fig. 4 Kaplan-Meier actuarial overall survival by tumor (T) stage

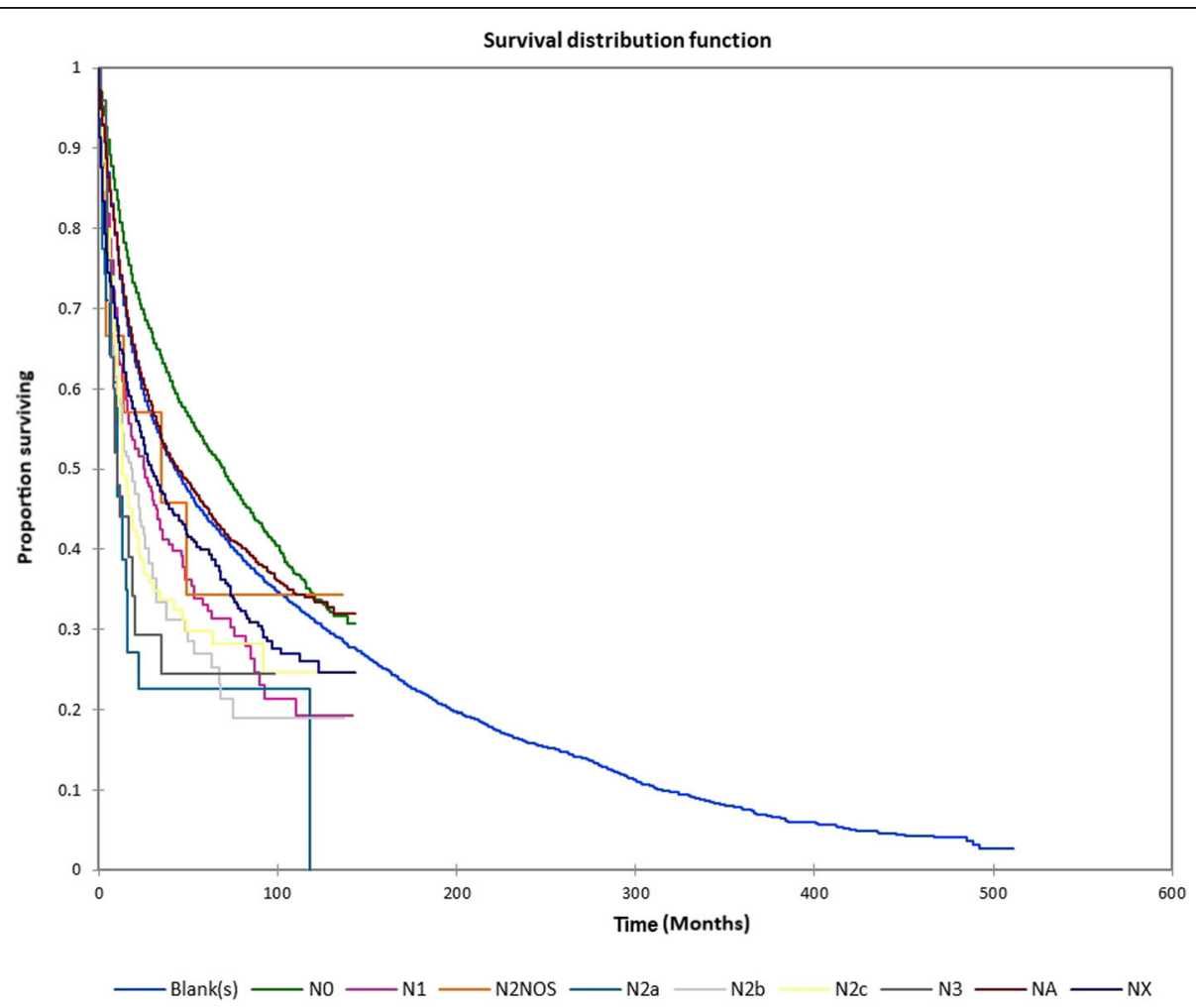

Fig. 5 Kaplan-Meier actuarial overall survival by nodal (N) stage 


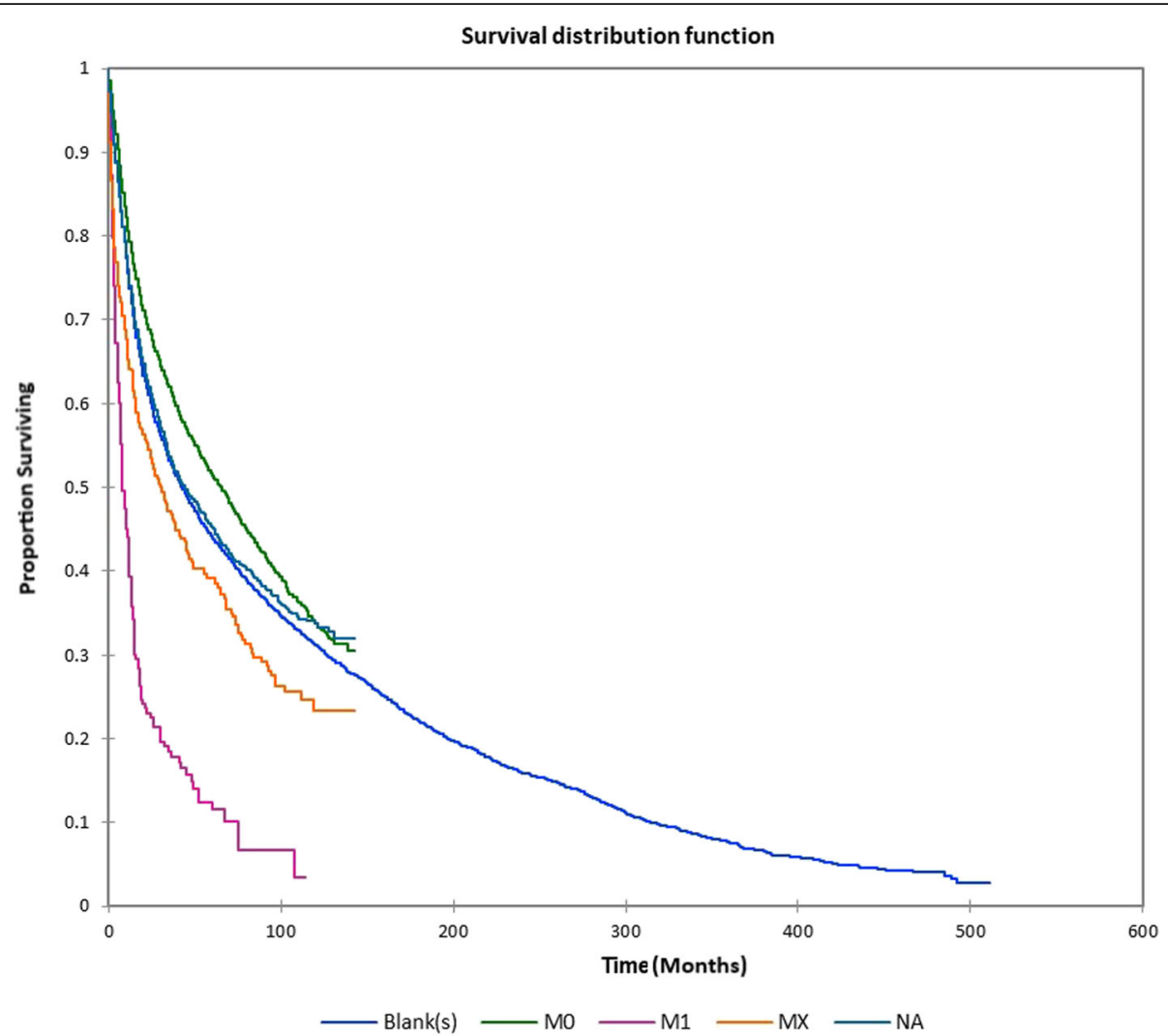

Fig. 6 Kaplan-Meier actuarial overall survival by distant metastasis (M) stage

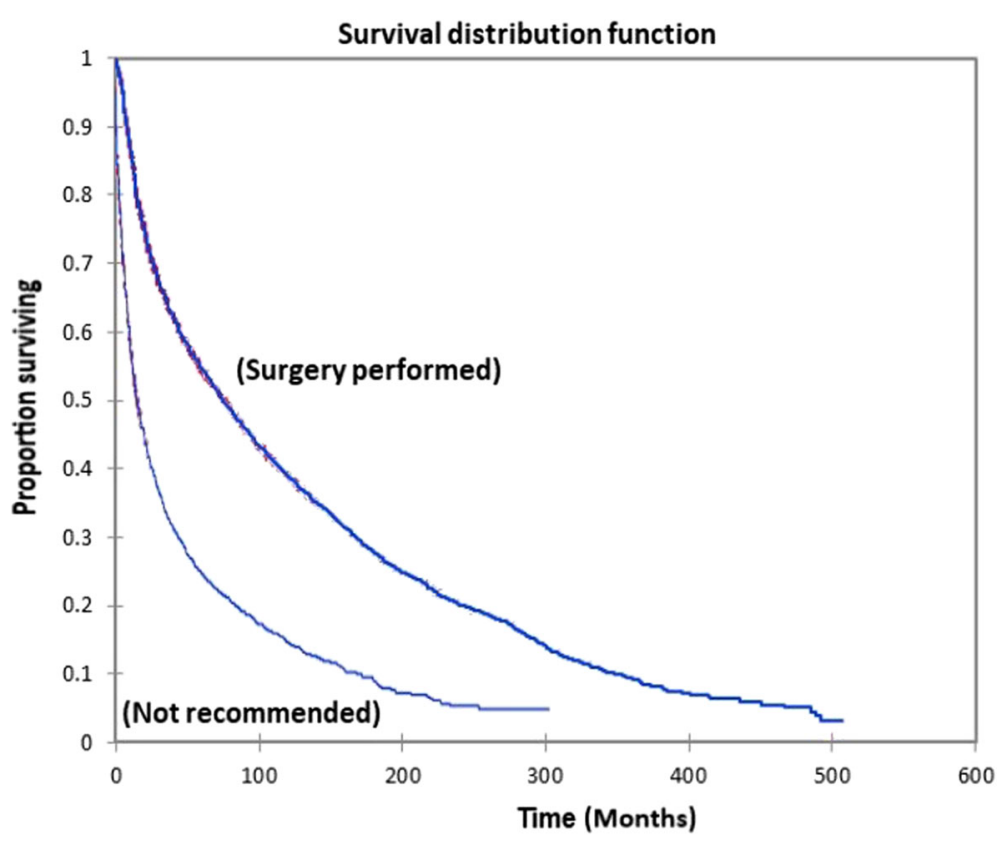

Fig. 7 Kaplan-Meier actuarial overall survival by surgical vs. nonsurgical treatment 
was not recommended vs. patients on whom surgery was performed $(p<0.0001)$. Figure 8 illustrates the KaplanMeier overall survival for patients by age at diagnosis. Survival decreased with increasing age at diagnosis $(p<0.0001)$. Figure 9 illustrates the Kaplan-Meier overall survival by sex. Survival was significantly lower for males than for females $(p=0.01)$. Figure 10 illustrates the Kaplan-Meier overall survival by patient race. Survival was significantly lower for black patients than white or other (Native American/Alaska Native/Asian/ Pacific Islander $)$ patient $(p<0.0001)$. Figure 11 illustrates the Kaplan-Meier overall survival by tumor grade. Survival decreased with increasing tumor grade $(p<0.0001)$. Figure 12 illustrates the Kaplan-Meier overall survival by tumor histopathological subtype. Survival was highest for nerve sheath tumors, gliomas, osseous and chondromatous neoplasms, germ cell neoplasms, synovial-like neoplasms, acinar cell neoplasms, adnexal and skin appendage neoplasms, and ductal and lobular neoplasms and lowest for nevi and melanomas $(p<0.0001)$. Multivariate analysis using linear regression demonstrated that age at diagnosis, race, sex, primary site, AJCC stage, surgical treatment vs. nonsurgical treatment, tumor grade, and $\mathrm{T}, \mathrm{N}$, and $\mathrm{M}$ stage all significantly affected survival $(p<0.0001$, Table 4$)$.

\section{Discussion}

Sinonasal and middle ear malignancies account for a minority of head and neck cancers. The relative rarity of these tumors makes population-based studies a favorable method for analyzing variables and factors affecting survival in these uncommon malignancies. Dutta et al. [1] noted an incidence of sinonasal malignancy of 0.83 per 100,000 people in their SEER 1973-2011-based study. They noted a male predominance (58.6\% of cases), and found that white patients comprised $81.5 \%$ of cases, while black patients accounted for $8.7 \%$. The present study using the 1973-2015 SEER database noted a similar proportion of male patients (58.9\%) and white patients (81.4\%), with a slightly larger proportion of black patients (9.4\%). They noted that squamous cell carcinoma was the most common sinonasal malignancy (41.9\%), and that the nasal cavity was the most common primary site (45.7\%). The present study found that squamous cell cancers comprised 50.9\% of the cohort, and nasal cavity tumors accounted for $46.1 \%$ of patients. The Dutta study found an overall 5-year disease specific survival for all sinonasal malignancies of $53.7 \%$, while in the present study the 5 -year overall survival was only $45.7 \%$. It is unclear what accounts for the lower overall survival in the present study

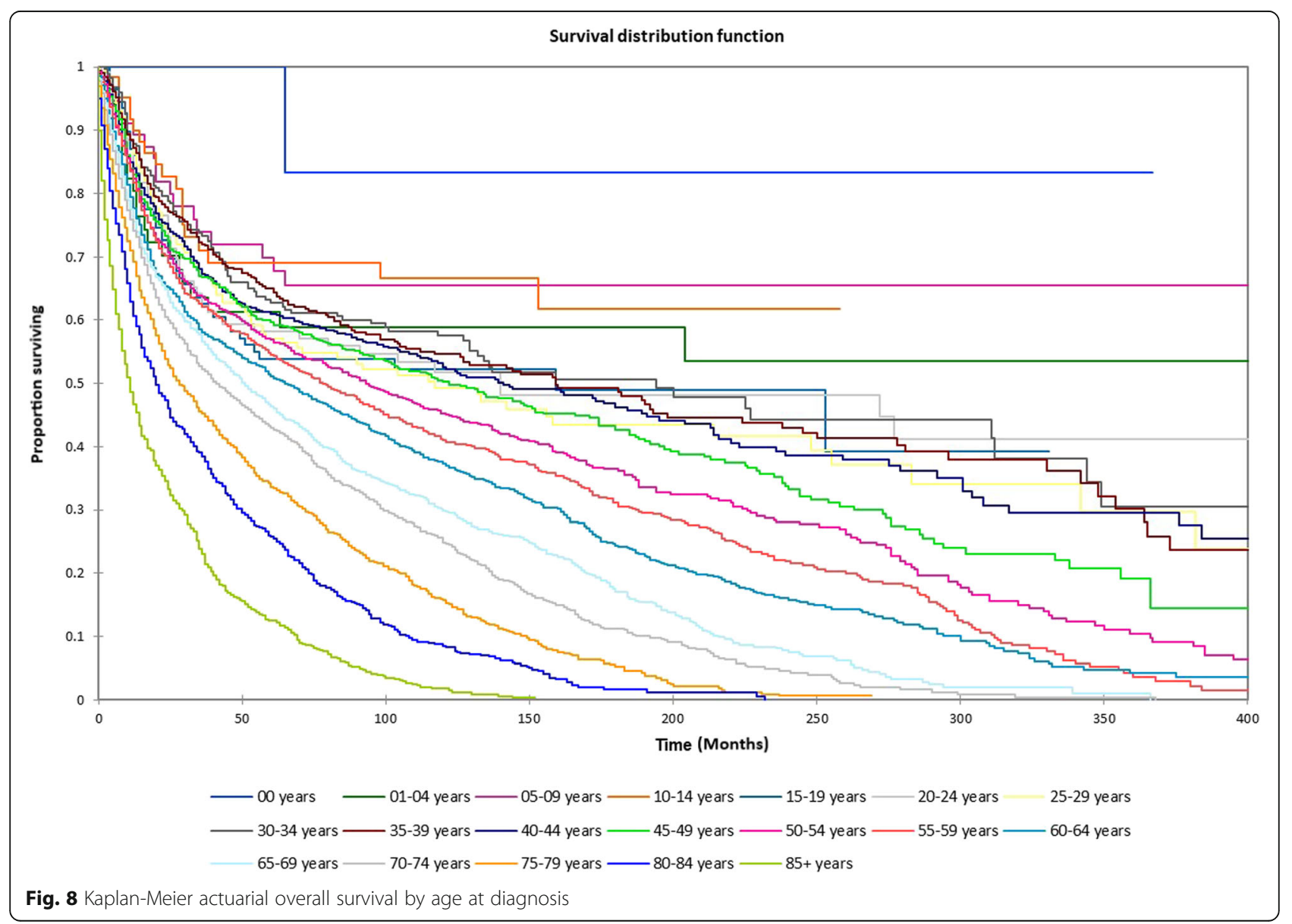




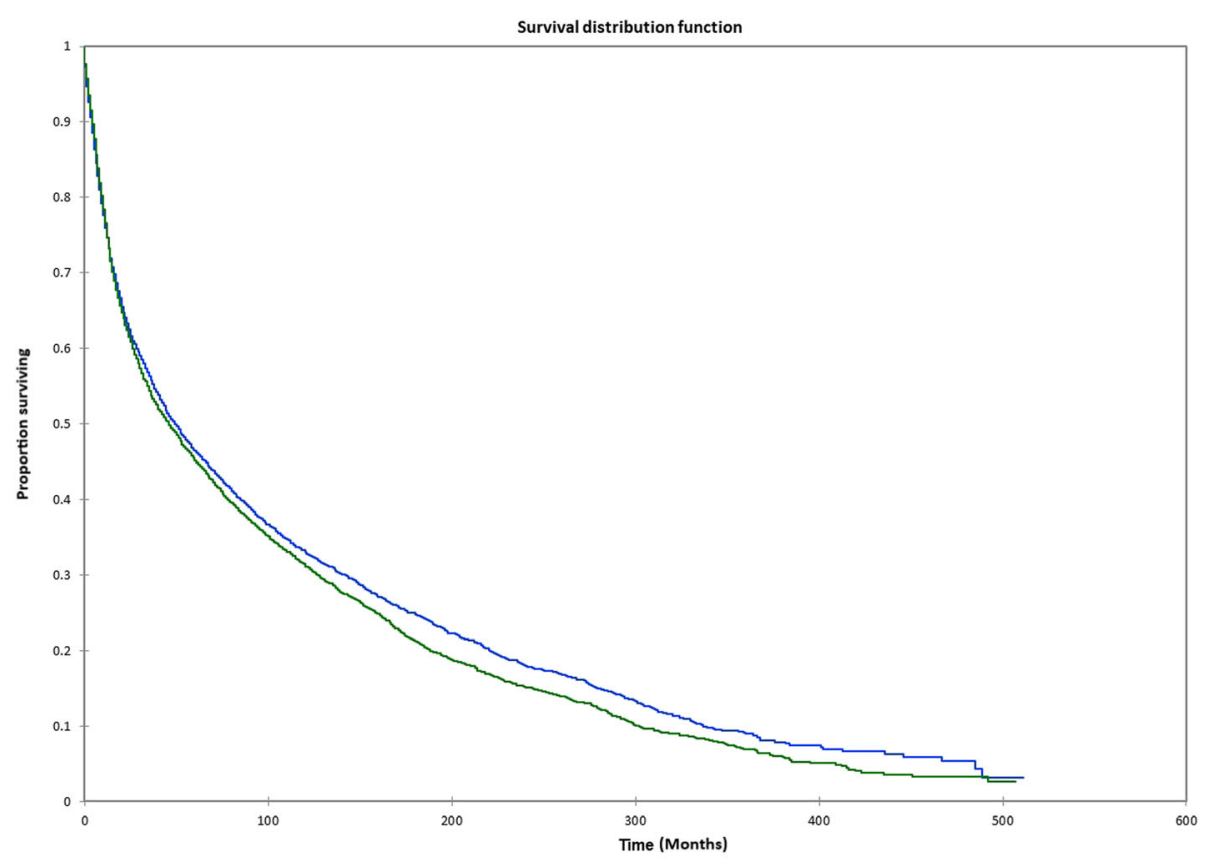

Fig. 9 Kaplan-Meier actuarial overall survival by patient sex

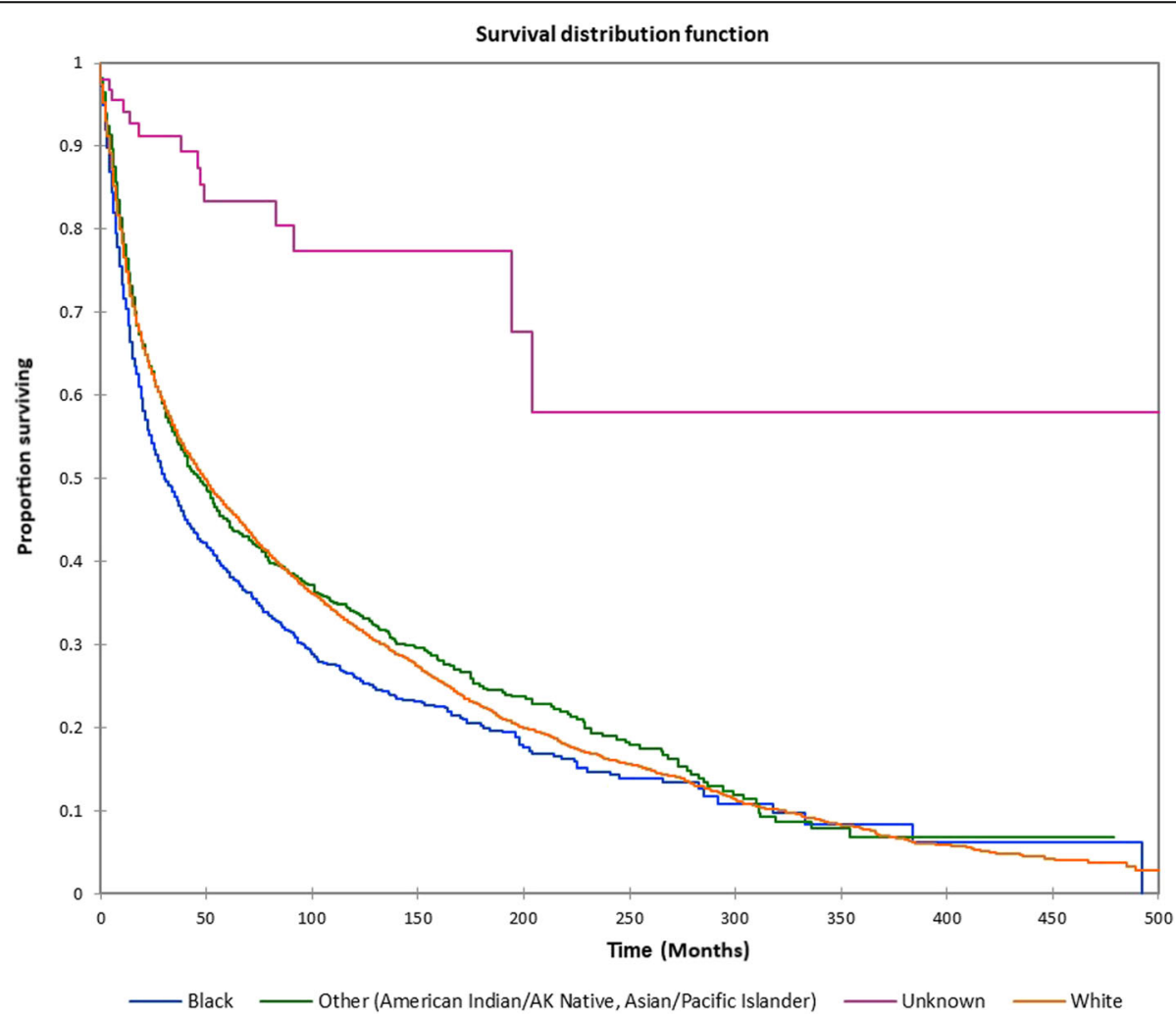

Fig. 10 Kaplan-Meier actuarial overall survival by patient race 


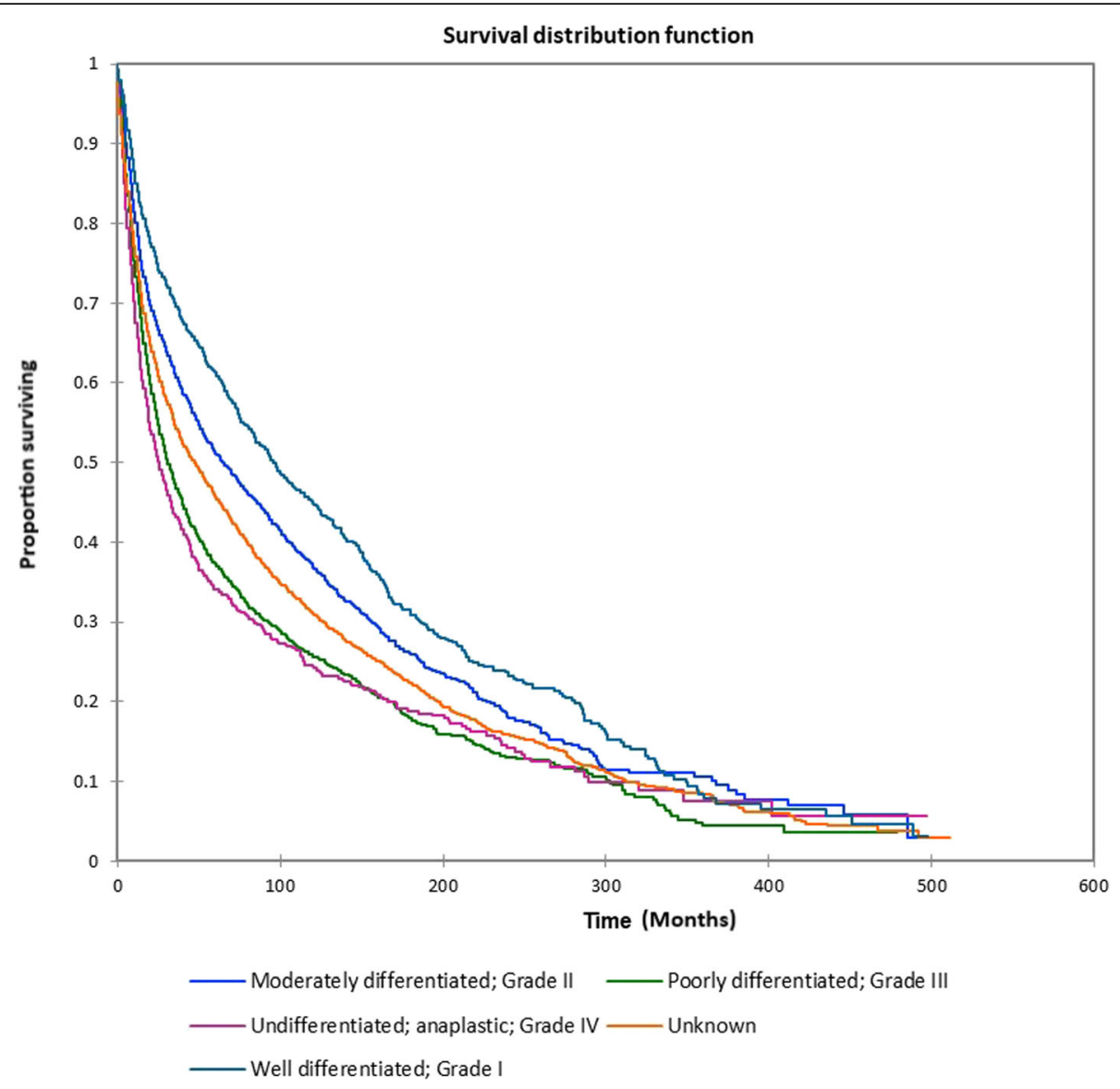

Fig. 11 Kaplan-Meier actuarial overall survival by tumor grade

relative to the Dutta study. The difference may be partially accounted for by the lower overall survival for middle ear malignancies. In their study of the 1973-2004 SEER database for middle ear malignancies Gurgel et al. [2] noted a 5 -year observed survival rate of only $36.4 \%$. In the present study the 5-year overall survival for the middle ear group was $44.4 \%$, somewhat higher than that found in the Gurgel study but similar to the overall 5-year survival for the entire cohort in the present study (45.7\%). Additionally, in the present study survival for middle ear tumors was significantly lower than that of nasal cavity tumors, but similar to or higher than paranasal sinus subsites. The higher proportion of squamous cell carcinomas in the present study relative to the Dutta study may also partially account for this difference, as the $50.9 \%$ of squamous cell neoplasms in the present study had a 5 -year overall survival (45\%) that was similar to that of the cohort as a whole (45.7\%). Of the patients with known $\mathrm{N}$ and $\mathrm{M}$ staging in the present study, the rates of nodal metastasis (4.4\%) and distant metastasis (1.5\%) were relatively low. Survival rates were particularly low for patients with melanoma in the present study (5-year survival $25.1 \%$, median survival time 51.3 months). This is consistent with previous studies [3] showing relatively dismal survival for sinonasal melanoma, with average survival on the order of 24 to 27 months.

The present study showed that on univariate analysis age at diagnosis, race, sex, primary site, histopathological subtype, AJCC overall stage, T, N, and M stage, surgical treatment vs. nonsurgical treatment, and tumor grade significantly affected survival, with all variables except histopathological subtype remaining significant on multivariate analysis. It is interesting that black patients showed significantly lower 5-, 10-, and 20-year overall survival (38.1\%, 26.6\%, and $14.8 \%$, respectively) than white patients (46.4\%, 32.0\%, and $16.0 \%$, respectively) and patients identified as other $(46.1 \%, 32.5 \%$, and $19.0 \%$, respectively). In their 2007 study using the 1988-2002 SEER database [4] Nichols and Bhattacharyya found a similar result, noting that black patients with oral tongue and glottic squamous cell carcinoma presented with higher $\mathrm{T}$ and $\mathrm{N}$ stage, and had shorter mean overall survival. Even after controlling for stage and treatment they noted that black patients demonstrated worse survival, implying that other factors influenced survival such as extrinsic socioeconomic factors or intrinsic genetic factors, etc. In the present study 


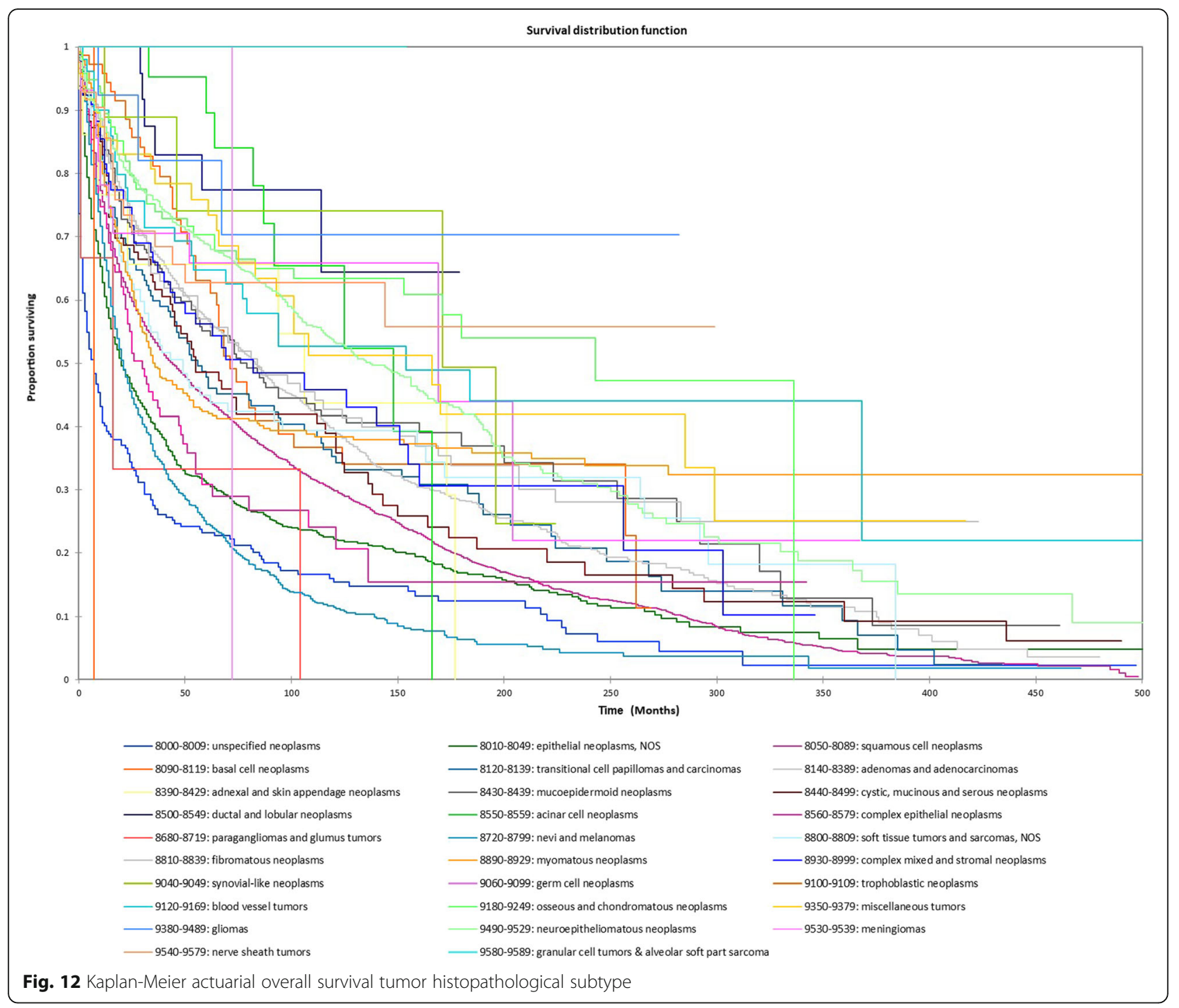

Table 4 Multivariate analysis results

\begin{tabular}{ll}
\hline Multivariate analysis variable & $p$-value \\
\hline Age at diagnosis & $p<0.0001$ \\
Race & $p<0.0001$ \\
Sex & $p<0.0001$ \\
Primary site & $p<0.0001$ \\
Histological subtype & $p=0.2$ \\
AJCC overall stage & $p<0.0001$ \\
Surgical vs. nonsurgical treatment & $p<0.0001$ \\
T stage & $p<0.0001$ \\
N stage & $p<0.0001$ \\
M stage & $p<0.0001$ \\
Tumor grade & $p<0.0001$ \\
\hline
\end{tabular}

race remained significant even on multivariate analysis, implying a similar effect as that seen in the Nichols study. Patel et al. [5] found a similarly lower 5-year survival for Hispanic whites and blacks (52\%) vs. non-Hispanic whites (64\%) in patients with sinonasal cancer in the 2000-2008 SEER database. They noted after multivariate analysis factors significantly affecting survival in addition to race were age, stage, histology, grade, comorbidity status, and standard of care, with lower stage and receiving standard of care multimodality treatment appropriate to stage being the most important prognostic factors.

The present study has limitations, including the retrospective nature of the data in the SEER database, the wide range of centers and states from which the data is compiled, and the presence of missing/unknown data for some variables such as $\mathrm{T}, \mathrm{N}$, and $\mathrm{M}$ stage. This makes recall and selection bias a possibility. Additionally, the inclusion of middle ear cancers (which are grouped with 
paranasal sinus and nasal cavity cancers in the SEER database) has the potential to add heterogeneity to the data. The fact that middle ear cancers account for only $3.1 \%$ of the cohort, and that the actuarial overall survival for the middle ear cohort is similar to the overall cohort is similar makes this less of a concern. The large number of patients in this 1973-2015 SEER cohort increases the reliability of the data, and the highly significant nature of the $p$-values noted on univariate and multivariate analysis, and the multiple studies demonstrating the utility of SEER-derived studies, makes the conclusions noted in the present study more reliable.

\section{Conclusions}

Malignancies of the nasal cavity, paranasal sinuses, and middle ear are relatively uncommon relative to more prevalent sites such as oral cavity and larynx. The present study demonstrated that patient race, sex, and age at diagnosis all significantly affected survival, with black patients, males, and patients older than 50 demonstrating worse survival. Additionally, tumor histopathological type, primary site, grade, surgical vs. nonsurgical treatment, and AJCC, T, N, and M stage all significantly affected survival. Overall 5-, 10-, and 20-year survival is relatively low, and surgical resection when possible combined with adjuvant therapy when indicated appears to provide the best chance for survival in patients with these rare malignancies.

\section{Abbreviations}

AJCC: American Joint Committee on Cancer; AK: Alaska; DFS: Disease-free survival; DSS: Disease-specific survival; G: Grade; M: Metastasis; N: Nodal; NA: Not available; OS: Overall survival; SEER: Surveillance, Epidemiology, and End Results; T: Tumor

\section{Availability of data and materials}

The data from the study is publicly available from the SEER database at https://seer.cancer.gov/.

\section{Authors' contributions}

MRG designed the study, performed the SEER database search, performedliterature, and wrote and edited the manuscript. The author read and approved the final manuscript.

\section{Ethics approval and consent to participate}

Not applicable.

\section{Consent for publication}

Not applicable.

\section{Competing interests}

The author declares that he has no competing interests.

\section{Publisher's Note}

Springer Nature remains neutral with regard to jurisdictional claims in published maps and institutional affiliations.
Received: 3 May 2018 Accepted: 31 July 2018

Published online: 09 August 2018

\section{References}

1. Dutta R, Dubal PM, Svider PF, Liu JK. Baredes S1, Eloy JA. Sinonasal malignancies: a population-based analysis of site-specific incidence and survival. Laryngoscope. 2015 Nov;125(11):2491-7.

2. Gurgel RK, Karnell LH, Hansen MR. Middle ear cancer: a population-based study. Laryngoscope. 2009 Oct;119(10):1913-7.

3. Gore MR, Zanation AM. Survival in Sinonasal Melanoma: A Meta-analysis. J Neurol Surg B Skull Base. 2012 Jun;73(3):157-62. https://doi.org/10.1055/s-0032-1301400.

4. Nichols AC, Bhattacharyya N. Racial differences in stage and survival in head and neck squamous cell carcinoma. Laryngoscope. 2007 May;117(5):770-5.

5. Patel ZM, Li J, Chen AY, Ward KC. Determinants of racial differences in survival for sinonasal cancer. Laryngoscope. 2016 Sep;126(9):2022-8.

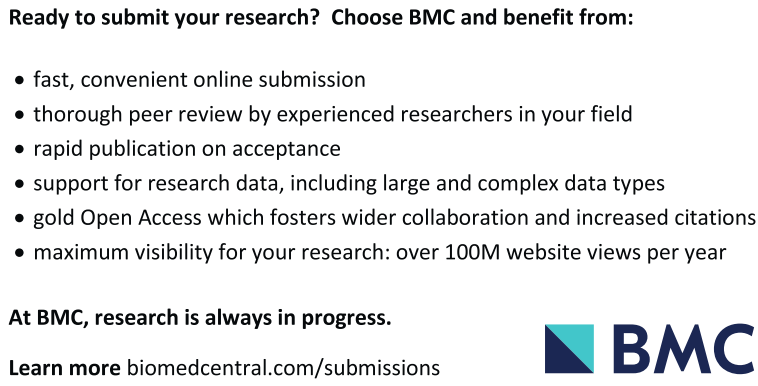

Ready to submit your research? Choose BMC and benefit from:

- fast, convenient online submission

- thorough peer review by experienced researchers in your field

- rapid publication on acceptance

- support for research data, including large and complex data types

- gold Open Access which fosters wider collaboration and increased citations

- maximum visibility for your research: over $100 \mathrm{M}$ website views per year

At BMC, research is always in progress.

Learn more biomedcentral.com/submissions 